\title{
Changes in Healthcare Spending After Diagnosis of Comorbidities Among Endometriosis Patients: A Difference-in-Differences Analysis
}

\author{
Andrew J. Epstein - Ahmed M. Soliman - Matthew Davis • \\ Scott J. Johnson · Michael C. Snabes · Eric S. Surrey
}

Received: August 7, 2017 / Published online: November 3, 2017

(C) The Author(s) 2017. This article is an open access publication

\section{ABSTRACT}

Introduction: We sought to characterize changes in healthcare spending associated with the onset of 22 endometriosis-related comorbidities.

Methods: Women aged 18-49 years with endometriosis $(N=180,278)$ were extracted from 2006-2015 de-identified Clinformatics ${ }^{\circledR}$ DataMart claims data. For 22 comorbidities, comorbidity patients were identified on the basis of having a first comorbidity diagnosis after their initial endometriosis diagnosis. Controls were identified on the basis of having no comorbidity diagnosis and were matched 1:1 to comorbidity patients on demographics and baseline spending. Total medical and pharmacy

Enhanced content To view enhanced content for this article go to http://www.medengine.com/Redeem/ 57CCF060385734F6.

Electronic supplementary material The online version of this article (doi:10.1007/s12325-017-0630-8) contains supplementary material, which is available to authorized users.

A. J. Epstein $(\varangle) \cdot$ M. Davis · S. J. Johnson

Medicus Economics, Milton, MA, USA

e-mail: andrew.epstein@medicuseconomics.com

A. M. Soliman · M. C. Snabes

AbbVie, North Chicago, IL, USA

E. S. Surrey

Colorado Center for Reproductive Medicine, Lone

Tree, CO, USA spending was measured during 12 months before and after each patient's index date (first comorbidity diagnosis for comorbidity patients, and equal number of days after earliest endometriosis claim for controls). Pre-post spending differences were compared using difference-in-differences linear regression. Total and comorbidity-related cumulative spending per patient for all endometriosis patients were calculated annually for the 5 years following endometriosis diagnosis.

Results: The number of endometriosis patients with each comorbidity varied between 121 for endometrial cancer and 16,177 for fatigue. Healthcare spending increased significantly with the onset of eight comorbidities: breast cancer, ovarian cancer, pregnancy complications, systemic lupus erythematosus/rheumatoid arthritis/Sjogren's/multiple sclerosis, infertility, uterine fibroids, ovarian cyst, and headache $[p<0.001$ except for headache $(p=0.045)]$. Spending decreased significantly for fatigue, cystitis/UTI, and eczema $[p<0.001$ except for fatigue $(p=0.048)]$ and was not statistically different for the other 11 comorbidities. Difference-in-differences estimates were significantly higher for comorbidity patients for all comorbidities except eczema $(p \leq 0.003)$. Mean 5-year total cumulative spending was $\$ 58,191$ per endometriosis patient, of which between $11 \%$ and $23 \%$ was attributable to comorbidity-related medical claims. 
Conclusion: For all but one of the 22 comorbidities associated with endometriosis, comorbidity onset was associated with a relative increase in total healthcare spending.

Funding: AbbVie Inc.

Keywords: Comorbidity; Endometriosis; Gynecology; Healthcare expenditures

\section{INTRODUCTION}

Medical care for the diagnosis and treatment of endometriosis patients in the USA was estimated to cost $\$ 22$ billion in 2002 [1]. Endometriosis-related spending is high for multiple reasons, including the high prevalence of the condition. Endometriosis is the third leading cause of gynecologic hospitalization [2], and endometriosis prevalence is estimated to be $6-10 \%$ or roughly $4-8$ million individuals among women in their reproductive years [3-6]. Another contributor to high spending is the frequent and resource-intensive medical care received by endometriosis patients. Within 1 year of endometriosis diagnosis, some $65 \%$ of patients with commercial insurance underwent a related surgical procedure, with costs ranging from over $\$ 4000$ for a diagnostic laparoscopy to over $\$ 11,000$ for an abdominal hysterectomy [7]; receipt of surgery is associated with an extra $\$ 12,000$ in direct medical cost and $\$ 3000$ in indirect medical cost in the first year [7]. A third reason is that, because endometriosis symptoms are non-specific, diagnosis is frequently delayed; reported mean time from initial symptoms to diagnosis is $4-12$ years in the USA $[8,9]$, leading to accrual of a substantial disease burden by the time of diagnosis [10-13].

Another potentially important aspect of endometriosis is its association with higher rates of a spectrum of comorbid conditions [14], including ovarian and other gynecological cancers [15], thyroid cancer, autoimmune diseases, asthma/atopic diseases, and cardiovascular diseases [16-21]. Medical care for each disease by itself can be expensive [22-25]. Having one or more comorbid conditions could lead to interactions with endometriosis in ways that necessitate additional medical care. While others have quantified the expenditures on medical treatment for endometriosis patients overall [10-13] or for a variety of comorbid conditions on their own [22-25], we are aware of only one study of women with endometriosis that analyzed the incremental impact of individual comorbidities on healthcare spending [12], and none that measured the contribution of all comorbidity-related care to overall healthcare expenditures. Clarifying the role played by comorbidities in endometriosis patients' spending trajectories could help providers and policymakers improve endometriosis care by increasing awareness of the potential benefits of prevention and early detection efforts.

The objective of this study was therefore to characterize the effects on healthcare cost associated with the onset of common endometriosis-related comorbidities individually and collectively, which ex ante were hypothesized to be substantial.

\section{METHODS}

\section{Data Source and Study Population}

Administrative data from the de-identified Clinformatics ${ }^{\circledR}$ DataMart database (OptumInsight, Eden Prairie, MN) were used in this study. These data consisted of commercial insurance medical service and pharmacy claims and enrollment records that covered January 2006 through September 2015. Their source was a large national health insurer's customers from around the USA. Relevant variables included patient demographics, clinical diagnoses recorded using codes from the International Classification of Diseases, Ninth Revision, Clinical Modification (ICD-9-CM), dates of service, and total amounts paid. The data used in this study were completely de-identified, and thus this study did not involve human subjects research. This article does not contain any studies with human participants or animals performed by any of the authors.

The initial study sample consisted of women aged 18-49 years at the time of their first observed medical claim with an endometriosis 
diagnosis. Consistent with prior work [12], endometriosis was identified as having at least two outpatient claims or at least one emergency room or inpatient claim with a diagnosis of endometriosis (ICD-9-CM 617.x) at any point during the study period with no washout period required. Some patients may have had interruptions in their insurance enrollment, which would lead to breaks in their claims history. For these patients, one continuous enrollment spell was selected randomly.

\section{Construction of Comorbidity-Specific Cohorts}

A set of 22 comorbid chronic conditions that frequently co-occur with endometriosis was selected from a published literature review and reviewed by a clinical expert (Dr. Craig A. Winkel, MD) [17]. The set includes comorbidities related to gynecological, mental health, gastrointestinal, cancer, and autoimmune conditions (Online Supplementary Material, Table S.1). A separate matched retrospective cohort was constructed for each of the 22 comorbidities and comprised "comorbidity patients" (those with a first claim with a diagnosis for that comorbidity that occurred after their initial endometriosis diagnosis) and "control patients" (endometriosis patients with no claims ever with that particular comorbidity diagnosis).

For comorbidity patients, the index date was defined as the earliest date of comorbidity diagnosis, which by construction had to occur after the earliest endometriosis date. For candidate control patients, the index date was calculated using an equal number of days after earliest endometriosis diagnosis as their matched comorbidity patient (Online Supplementary Material, Fig. S.1). Eligible comorbidity and control patients were required to have at least 365 days of continuous coverage both before and after their index dates, divided into the baseline period (365 days before index date) and the follow-up period (365 days after index date).

Matching between control patients and comorbidity patients was performed on a 1:1 basis with replacement. Matching was exact on patients' Census division of residence, insurance plan type, and age at endometriosis diagnosis ( \pm 1 year). Up to 10 candidate controls were selected for each comorbidity patient on the basis of their total spending in the baseline period (i.e., the 365-day period prior to the index date), consisting of the first five closest control patients with baseline total spending within $\$ 5000$ of the comorbidity patient's and the second five closest control patients with baseline total spending within a variable caliper of $\$ 1000$ to $\$ 5000$. (The caliper was calculated for each comorbidity patient as $\min [5000$, $\max (1000,10 \% \times$ baseline spending)].) From these 10 or fewer candidates, the single closest control patient was selected with the smallest total Euclidean distance calculated across the four components of total baseline spending: inpatient, emergency department, outpatient, and pharmacy.

In the main analysis, comorbidity patients were identified on the basis of the presence of at least one medical claim with a given comorbidity. As a robustness check, analyses were repeated after identifying comorbidity patients on the basis of the presence of at least two distinct medical claims. Patients were excluded from analysis if their total spending in the baseline or follow-up periods was less than zero (which might occur from, e.g., billing corrections) or they lacked continuous enrollment for the 365 days before and after their index date. Comorbidity patients with no eligible control patient matched were also excluded (Online Supplementary Material, Table S.1).

\section{Statistical Analysis}

The primary endpoint in this analysis was the patient-level change in total healthcare spending from the baseline period (365 days before index date) to the follow-up period (365 days after index date), calculated as the post-index expenditure minus the pre-index expenditure. Total spending in each period was the sum of all payments for medical and pharmacy claims starting in that period and was inflated to 2015 US dollars using the US Personal Health Care Index and its component price indexes [26]. 
To assess the quality of the match, standardized differences were calculated between comorbidity patients and matched controls [27]. A difference-in-differences analytic framework was adopted, in which the difference between pre- and post-index-date spending levels was compared to zero separately for comorbidity patients and controls; these differences were subsequently compared between comorbidity patients and controls using linear regression. Robust regression standard errors were computed to account for heteroskedasticity and clustering by match pair [28].

An auxiliary analysis was conducted to help understand the contribution of comorbidity-related care to overall spending on healthcare for endometriosis patients. Using data on the initial sample of all endometriosis patients aged 18-49 years, mean cumulative spending per patient was calculated for the full duration of each of the 1-, 2-, 3-, 4-, and 5-year periods following a patient's earliest endometriosis claim. For each of the five periods, only patients with continuous eligibility through that period were included.

Statistical significance was based on twosided tests with $\alpha=0.05$. Analyses were conducted using Stata MP 14.1 (College Station, TX).

\section{RESULTS}

There were 180,278 patients in the initial sample of women with endometriosis (Table 1). Mean age was 37 years; $65 \%$ were in point-of-service insurance plans; and 51\% lived in the South Census region. Across the 22 comorbidity-specific matched cohorts, there were 54,070 unique endometriosis patients with at least one comorbidity observed during their available follow-up (30\% of all endometriosis patients). Baseline characteristics among this subset were similar. As unique patients frequently had multiple comorbidities, the 54,070 comorbidity patients accounted for 112,307 patient-comorbidity instances; these were matched 1:1 with control patients. (The sample selection process is documented in Online Supplementary Material, Table S.1.)
Table 1 Baseline characteristics of endometriosis patients

\begin{tabular}{lll}
\hline Variable name & $\begin{array}{l}\text { All } \\
\text { endometriosis } \\
\text { patients }\end{array}$ & $\begin{array}{l}\text { Endometriosis } \\
\text { patients with } \geq \\
\text { comorbidity }\end{array}$ \\
\hline Age at endometriosis diagnosis & $37.4(7.3)$ \\
Mean (SD) & $36.9(7.6)$ & $38.0(11.0)$ \\
Median (IQR) & $38.0(12.0)$ & $15.5 \%(8382)$ \\
Insurance product, $\%(\mathrm{~N})$ & $13.6 \%(24,530)$ & $13.4 \%(7279)$ \\
EPO & $14.5 \%(26,074)$ & $0.0 \%(8)$ \\
HMO & $0.1 \%(130)$ & $0.1 \%(49)$ \\
Indemnity & $0.1 \%(204)$ & $64.9 \%(35,135)$ \\
Other & $65.0 \%(117,187)$ \\
POS & $6.7 \%(12,153)$ & $5.9 \%(3217)$ \\
PPO &
\end{tabular}

Census region, \% $(\mathrm{N})$

$\begin{array}{lll}\text { Northeast } & 8.6 \%(15,454) & 9.0 \%(4843) \\ \text { Midwest } & 24.1 \%(43,491) & 23.5 \%(12,702) \\ \text { South } & 51.3 \%(92,508) & 52.0 \%(28,143) \\ \text { West } & 15.9 \%(28,717) & 15.5 \%(8372) \\ \text { Missing } & 0.1 \%(103) & 0.0 \%(10)\end{array}$

Year of earliest endometriosis diagnosis, \% (N)

\begin{tabular}{lll}
2006 & $15.1 \%(27,191)$ & $20.0 \%(10,831)$ \\
2007 & $12.2 \%(22,080)$ & $15.0 \%(8132)$ \\
2008 & $11.3 \%(20,289)$ & $14.0 \%(7589)$ \\
2009 & $10.6 \%(19,124)$ & $13.3 \%(7194)$ \\
2010 & $9.4 \%(16,920)$ & $11.2 \%(6077)$ \\
2011 & $9.2 \%(16,540)$ & $10.1 \%(5476)$ \\
2012 & $8.8 \%(15,813)$ & $8.5 \%(4594)$ \\
2013 & $9.1 \%(16,332)$ & $5.9 \%(3214)$ \\
2014 & $8.0 \%(14,501)$ & $1.8 \%(963)$ \\
2015 & $6.4 \%(11,488)$ & $0.0 \%(0)$ \\
Sample size & 180,278 & 54,070 \\
\hline
\end{tabular}

Unit of analysis is unique patient

$S D$ standard deviation, IQR interquartile range, EPO exclusive provider organization, $H M O$ health maintenance organization, $P O S$ point-of-service, $P P O$ preferred provider organization 
Observed covariates were well balanced between the comorbidity patients and their matched controls in the 22 comorbidity cohorts. By construction, balance was perfect on Census region and insurance plan type. Standardized differences were less than $1 \%$ for patient age and less than 3\% for baseline total spending for all cohorts. Mean pre-index-date spending was similar between comorbidity and control patients in the same cohort. Across the 22 cohorts, baseline total spending differed between the two types of patients by $\$ 325$ on average, with a range of $\$ 182$ (eczema) to $\$ 547$ (stress).

The magnitude and direction of changes in 1-year mean spending per comorbidity patient from before to after the index date are presented in Table 2. Among comorbidity patients, spending increased by a statistically significant amount after onset of eight of 22 comorbidities: breast cancer $(\$ 54,453)$, ovarian cancer $(\$ 19,881)$, pregnancy complications (\$7728), systemic lupus erythematosus/rheumatoid arthritis/Sjogren's/multiple sclerosis (\$5073), infertility (\$4630), uterine fibroids (\$4007), ovarian cyst (\$3866), and headache (\$373). At the same time, spending decreased significantly for three comorbidities: fatigue $(-\$ 385)$, cystitis/urinary tract infection (UTI) $(-\$ 1312)$, and eczema $(-\$ 1626)$. Spending was not significantly different for the other 11 comorbidities.

Difference-in-differences estimates of the impact of comorbidity onset on 1-year mean spending per patient are reported in Fig. 1 and Online Supplementary Material, Table S.2. For all comorbidities but eczema, spending increased relatively more among comorbidity patients than control patients. These relative increases were mostly in the range of $\$ 4000-7000$, but were larger for breast cancer $(\$ 61,210)$, ovarian cancer $(\$ 27,136)$, and endometrial cancer $(\$ 14,227)$.

To check the sensitivity of results to the criteria for identifying whether a comorbidity was present, analyses were repeated after requiring patients to have at least two separate claims with a diagnosis code for a comorbidity. Results were consistent with, if not stronger than, those from the main analyses (Online Supplementary Material, Table S.3). Mean total spending per patient grew from 1 year before comorbidity onset to 1 year after for 12 comorbidities: breast cancer $(\$ 65,754)$, ovarian cancer $(\$ 35,407)$, endometrial cancer $(\$ 16,993)$ systemic lupus erythematosus/rheumatoid arthritis/Sjogren's/multiple sclerosis (\$9671), pregnancy complications (\$9088), uterine fibroids (\$8487), ovarian cyst (\$6446), infertility (\$5389), constipation (\$3114), headache (\$1427), depression (\$983), and fibromyalgia (\$843). Before- and after-onset spending levels were not significantly different for the remaining 10 comorbidities. Likewise, in the difference-in-differences analyses, for all comorbidities but mood disorders and stress, spending increased relatively more among comorbidity patients than control patients by statistically significant amounts ranging from $\$ 2843$ (eczema) to $\$ 73,093$ (breast cancer) (Online Supplementary Material, Table S.4).

Cumulative spending since the earliest observed endometriosis claim was examined in an auxiliary analysis of all endometriosis patients regardless of their comorbidity status (Table 3). In the first year after endometriosis diagnosis, mean total spending per patient (including medical and pharmacy claims) for the 108,452 patients with at least a year of follow-up was $\$ 20,171$, of which $\$ 3203$ (16\%) was for medical claims with a principal diagnosis code for one of the 22 comorbidities and $\$ 6609$ (33\%) was for medical claims with a comorbidity diagnosis code in any position. Among the 19,766 patients with at least 5-year post-diagnosis follow-up, total cumulative spending over the entire 5-year post-diagnosis period was $\$ 58,191$, of which between $\$ 6187$ (11\%) and $\$ 13,332$ (23\%) came from comorbidity-related medical claims.

\section{DISCUSSION}

As we and others have found [14-21], there are a number of comorbidities in women with endometriosis. In trying to understand the meaning and implications of these comorbidities, one important dimension is the economic burden of the diseases which are comorbid in endometriosis patients. In a large sample of 
Table 2 365-day total spending before and after index date for comorbidity patients

\begin{tabular}{|c|c|c|c|c|c|c|}
\hline Comorbidity & $\mathbf{N}$ & $\begin{array}{l}\text { Mean spending } \\
365 \text { days before } \\
\text { index date }(\$)\end{array}$ & $\begin{array}{l}\text { Mean spending } \\
365 \text { days after } \\
\text { index date }(\$)\end{array}$ & $\begin{array}{l}\text { (After-before) } \\
\text { spending } \\
\text { difference (\$) }\end{array}$ & P-value & $95 \% \mathrm{CI}$ \\
\hline $\begin{array}{l}\text { Infertility, } \\
\text { subfertility }\end{array}$ & 3442 & 11,679 & 16,309 & 4630 & $<0.001$ & [3954; 5306] \\
\hline Ovarian cyst & 9566 & 11,245 & 15,111 & 3866 & $<0.001$ & [3316; 4416] \\
\hline Uterine fibroids & 6745 & 10,064 & 14,072 & 4007 & $<0.001$ & {$[3352 ; 4662]$} \\
\hline PID & 721 & 17,256 & 17,927 & 671 & 0.47 & {$[-1144 ; 2485]$} \\
\hline $\begin{array}{l}\text { Pregnancy } \\
\text { complications }\end{array}$ & 5384 & 13,132 & 20,860 & 7728 & $<0.001$ & {$[7130 ; 8325]$} \\
\hline $\begin{array}{l}\text { Interstitial } \\
\text { cystitis }\end{array}$ & 1027 & 17,615 & 19,060 & 1445 & 0.09 & {$[-220 ; 3110]$} \\
\hline Cystitis, UTI & 14,826 & 14,246 & 12,934 & -1312 & $<0.001$ & {$[-1668 ;-956]$} \\
\hline IBS & 4477 & 15,708 & 15,430 & -278 & 0.36 & {$[-871 ; 316]$} \\
\hline $\begin{array}{l}\text { Constipation, } \\
\text { dyschezia }\end{array}$ & 6530 & 16,098 & 16,635 & 538 & 0.10 & {$[-111 ; 1186]$} \\
\hline Eczema & 1594 & 12,528 & 10,901 & -1626 & $<0.001$ & {$[-2405 ;-847]$} \\
\hline $\begin{array}{l}\text { Depression, } \\
\text { anxiety }\end{array}$ & 11,682 & 13,205 & 13,350 & 145 & 0.50 & {$[-276 ; 566]$} \\
\hline Mood disorders & 212 & 17,510 & 18,146 & 636 & 0.61 & {$[-1837 ; 3110]$} \\
\hline Stress & 429 & 14,977 & 16,212 & 1235 & 0.32 & {$[-1217 ; 3687]$} \\
\hline Fatigue & 16,177 & 12,280 & 11,894 & -385 & 0.048 & {$[-767 ;-3]$} \\
\hline Fibromyalgia & 8011 & 14,369 & 14,639 & 271 & 0.28 & {$[-217 ; 758]$} \\
\hline Headache & 13,435 & 12,249 & 12,622 & 373 & 0.045 & {$[8 ; 738]$} \\
\hline Ovarian cancer & 264 & 19,992 & 39,873 & 19,881 & $<0.001$ & {$[11,490 ; 28,272]$} \\
\hline $\begin{array}{l}\text { Endometrial } \\
\text { cancer }\end{array}$ & 121 & 22,089 & 26,093 & 4004 & 0.26 & {$[-3029 ; 11,037]$} \\
\hline Breast cancer & 294 & 17,561 & 72,014 & 54,453 & $<0.001$ & {$[46,869 ; 62,038]$} \\
\hline Hypothyroidism & 6378 & 13,472 & 13,304 & -168 & 0.52 & {$[-686 ; 349]$} \\
\hline $\begin{array}{l}\text { SLE, RA, } \\
\text { Sjogren's, MS }\end{array}$ & 595 & 18,491 & 23,563 & 5073 & $<0.001$ & {$[2643 ; 7502]$} \\
\hline Sprue & 397 & 15,693 & 15,581 & -112 & 0.92 & {$[-2255 ; 2031]$} \\
\hline
\end{tabular}

Total spending amounts are reported in 2015 US dollars

Index date defined as date of earliest claim with comorbidity diagnosis code

PID pelvic inflammatory disorder, UTI urinary tract infection, IBS irritable bowel syndrome, SLE systemic lupus erythematosus, $R A$ rheumatoid arthritis, $M S$ multiple sclerosis, $C I$ confidence interval 


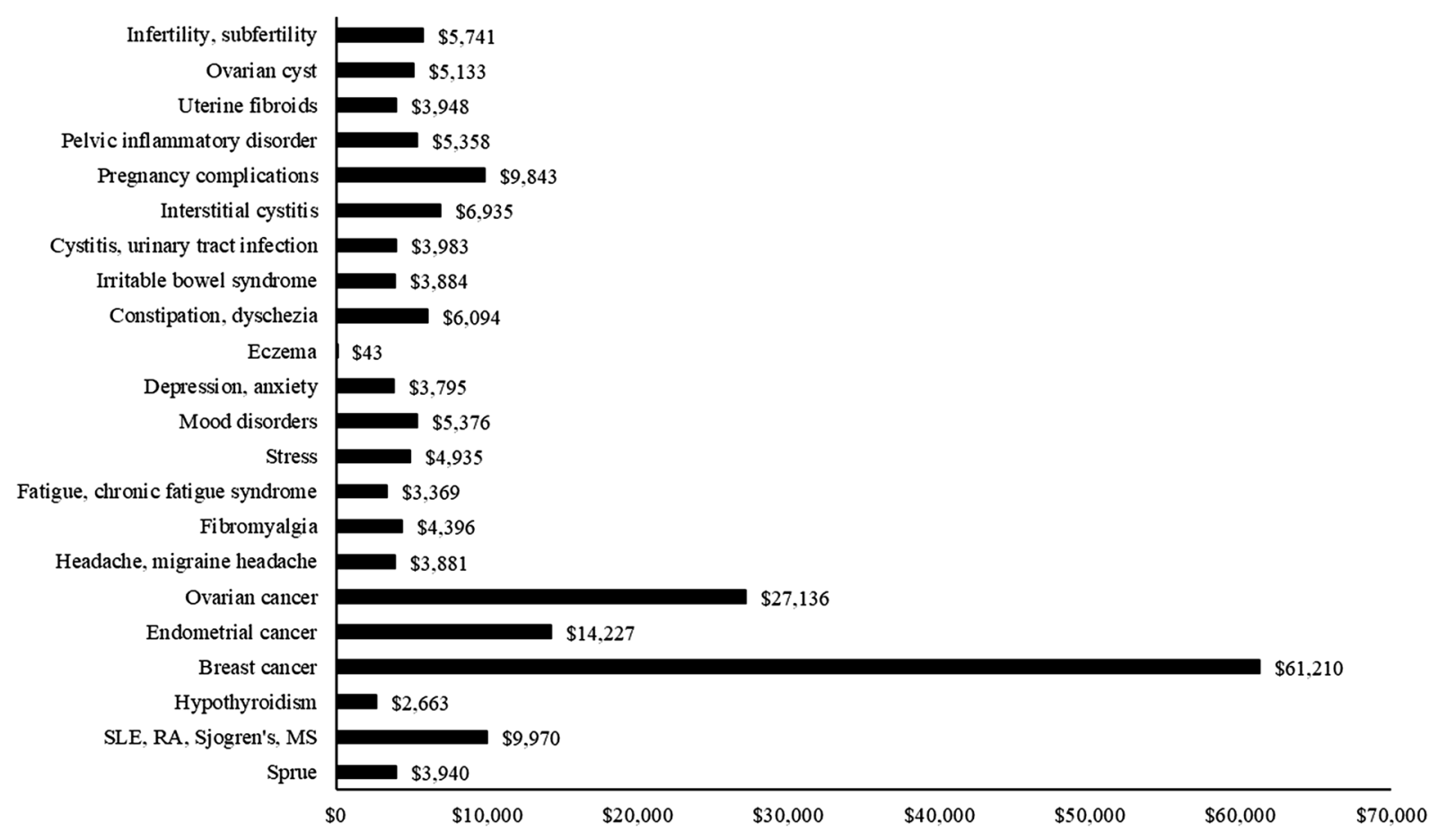

Fig. 1 Difference-in-differences in 365-day total spending for comorbidity patients vs. controls. $P \leq 0.003$ for all except eczema $(P=0.94)$. Total spending amounts are

commercially insured women with endometriosis, our study examined the effects of 22 comorbidities on healthcare spending. From the year before to the year after comorbidity onset, spending grew in absolute terms for eight comorbidities and declined for three. When compared with matched sets of control patients who had endometriosis but did not experience the focal comorbidity, comorbidity onset was associated with positive and significant relative spending growth for 21 of the 22 comorbid conditions. Relative spending increases were mostly in the range of \$4000-7000, but for breast, endometrial, and ovarian cancers, cost increments were substantially larger.

Note that, in all comorbidity cohorts but one, mean spending among control patients decreased from baseline to follow-up (Online Supplementary Material, Table S.2), illustrating the mean reversion inherent in selecting patients on the basis (in part) of their baseline spending levels. To the extent the control patients' experience represents an accurate reported in 2015 US dollars, SLE systemic lupus erythematosus, $R A$ rheumatoid arthritis, $M S$ multiple sclerosis

counterfactual for the comorbidity patients, we would expect absolute spending to decrease among endometriosis patients in the absence of a comorbidity. The absolute reductions in spending associated with fatigue, cystitis/UTI, and eczema are therefore best explained by the reduction attributable to mean reversion exceeding any increase attributable to comorbidity onset. At the same time, the contemporaneous absolute reductions in spending among the matched control patients were larger than the decreases among comorbidity patients, resulting in difference-in-differences estimates in mean spending that were net positive.

Mirkin et al. evaluated the effects of comorbidities on spending in a population of endometriosis patients using US private payer insurance claims data for 1999-2003 [12]. (For comparability, spending amounts from other studies cited here have been adjusted for inflation to 2015 US dollars using the US Personal Health Care Index.) For each of seven comorbidities (abdominal pain, chronic fatigue syndrome, depression, infertility, interstitial 
Table 3 Mean cumulative spending per patient by years since endometriosis diagnosis

\begin{tabular}{llllll}
\hline Cumulative spending category & \multicolumn{5}{l}{ Years since endometriosis diagnosis } \\
\cline { 2 - 6 } & Year 1 & Year 2 & Year 3 & Year $\mathbf{4}$ & Year 5 \\
\hline Total (medical + pharmacy) spending $(\$)$ & 20,171 & 30,442 & 39,842 & 48,958 & 58,191 \\
Medical spending $(\$)$ & $100 \%$ & $100 \%$ & $100 \%$ & $100 \%$ & $100 \%$ \\
& 18,340 & 26,795 & 34,339 & 41,526 & 48,676 \\
Comorbidity-related medical spending (principal diagnosis code) $)(\$)$ & 3203 & 4127 & 4895 & 5603 & 6187 \\
Comorbidity-related medical spending (any diagnosis code) $(\$)$ & $16 \%$ & $14 \%$ & $12 \%$ & $11 \%$ & $11 \%$ \\
Pharmacy spending $(\$)$ & 6609 & 8599 & 10,330 & 11,871 & 13,332 \\
Sample size & $33 \%$ & $28 \%$ & $26 \%$ & $24 \%$ & $23 \%$ \\
\hline
\end{tabular}

Spending amounts are reported in 2015 US dollars and reflect mean total spending since endometriosis diagnosis per patient Percentages are calculated relative to total spending amounts within column

Year-specific samples comprise endometriosis patients with continuous enrollment through the end of that year regardless of comorbidity status

cystitis, irritable bowel syndrome, migraine), they found that the average annual medical spending in 2003 was between $\$ 1700$ and $\$ 5600$ higher for endometriosis patients with the specific comorbidity than for the average endometriosis patient overall (regardless of comorbidity status). Their estimates are somewhat smaller than what we found for the same conditions. Mirkin et al.'s estimate of annual spending on, for example, interstitial cystitis was about $\$ 5600$ compared with our difference-in-differences estimate of about $\$ 7000$, while their estimate for infertility was about $\$ 4000$ smaller than ours ( $\$ 5741$ vs. $\$ 1690$ ). One possible explanation for the apparent divergence in results is that treatment patterns for comorbidities may have increased in intensity (or price) between 2003 and 2015 by more than the inflation adjuster. Additionally, Mirkin et al. examined spending among patients with prevalent comorbidities in a single year, whereas we studied spending in the year after a comorbidity's initial observed onset (albeit without a washout period); the results might be reconciled if the cost burden of a comorbidity decreases over time since its onset. Another difference is that their comparison group included all endometriosis patients whereas ours consisted of a matched set based on baseline characteristics.

The other principal finding from our study was that, as cumulative total spending per patient on healthcare after the first endometriosis claim grew from roughly $\$ 20,000$ in the first year after diagnosis to three times that by the end of the fifth year, cumulative healthcare spending related to the 22 study comorbidities also increased, but only by a factor of 2. Using a conservative assessment where only medical claims documenting a comorbidity in the first diagnosis position were included, cumulative comorbidity-related spending per endometriosis patient grew from \$3203 in the first year (16\% of total) to $\$ 6187$ in the first 5 years ( $11 \%$ of total). In reality, comorbidities are likely responsible for a greater share of total spending, as the above estimates ignore pharmacy spending (for which no diagnosis codes 
were available) and medical claims with comorbidities in a secondary diagnosis position. Using a less conservative approach that includes the latter yields estimates of comorbidity-related care that account for $33 \%$ and $23 \%$ of cumulative total spending during the 1- and 5 -year periods, respectively, after the initial endometriosis claim.

Prior studies have measured the economic burden associated with endometriosis [10]. Mirkin et al. found that total direct medical spending among endometriosis patients in 2003 averaged over $\$ 11,000$ per year, which was notably higher than medical spending among women in general (roughly $\$ 7000$ per year) [12]. Fuldeore et al. took a somewhat different approach with the same data over 2000-2010 and calculated mean spending per patient stratified by year relative to the initial endometriosis diagnosis [11]. Total medical and pharmacy spending was over $\$ 14,000$ in the first year after diagnosis and about $\$ 7000$ in each of the second through fifth years. These estimates are somewhat lower than our estimate of $\$ 20,171$ in the first year and $\$ 9000-10,000$ annually in the second through fifth years (i.e., as measured by the year-over-year differences in cumulative spending). Nevertheless, no prior studies reported on the share of total spending attributable to comorbidity-related care.

Our findings on the sizeable impact of comorbidities on healthcare spending among women with endometriosis underscore two important points for providers and payers: this patient population exhibits pronounced heterogeneity in expected resource use, and there are potential benefits of comorbidity prevention and early detection efforts. Additional implications of these findings for clinical practice depend largely on the relationship between endometriosis diagnosis and development of subsequent comorbidities [29]. Selection of the 22 comorbidities to study was based on epidemiological evidence of endometriosis-comorbidity associations. Although some of the associations are well known (e.g., pelvic pain, ovarian cysts, infertility), others rely on an evidence base that is not definitive but is growing (e.g., cancer, gastrointestinal disease) $[15,16,18,30,31]$. Moreover, the nature of their relationship with endometriosis likely varies across individual comorbidities. In some cases, there may be a direct connection via a common pathophysiology or generalized inflammatory state, while others may be coincidental. This investigation cannot differentiate between these two phenomena. The links between endometriosis and its comorbidities are complicated and await greater understanding of the pathophysiology of endometriosis.

Our findings must be interpreted in the light of the study's limitations. One set of limitations stems from the use of administrative claims data, which provide limited clinical detail and may be susceptible to coding errors and omissions. The presence of endometriosis was identified using ICD-9-CM diagnosis codes and could not be confirmed on the basis of standard diagnostic criteria, surgical diagnosis with or without histology results, which in practice are obtained only for some patients and were not available in the study data for any [3]. Similar concerns pertain to the accuracy of relying on diagnosis codes to identify the presence of comorbid conditions.

Another set of limitations are associated with features of the study design. In analyzing the impact on spending of individual comorbidities one at a time, follow-up was restricted to 365 days after the initial comorbidity diagnosis, and no adjustment was made for the possible influence of other comorbidities occurring alongside the focal comorbidity, or among control patients, during the baseline or follow-up periods. Second, the sample sizes for some comorbidities (e.g., ovarian, endometrial, and breast cancer, mood disorders) were small, which may have exacerbated the role of outliers in calculating spending levels. Third, in part because of the small sample sizes, our analyses did not account for or stratify by endometriosis location. Fourth, in trying to isolate the effect of comorbidities on spending, the study data lacked the granularity to determine how much of a claim's spending was attributable to a coded comorbidity vs. other diagnosis codes on that claim.

Generalizability is a further limitation. The patient sample included commercially insured patients aged 18-49 years from a single payer's 
experience, over half of whom resided in the South Central Census region. Thus, these patients may not represent the overall female population of reproductive age or of younger or older females. Likewise, we analyzed 22 comorbidities, which do not necessarily reflect all endometriosis-related comorbidities. Moreover, with only a year of follow-up after the earliest endometriosis claim, our data do not reflect a patient's lifetime risk of comorbidities. We suspect the short follow-up explains why only $30 \%$ of the full endometriosis sample experienced a comorbidity.

\section{CONCLUSION}

While large healthcare expenditures of women with endometriosis have been documented previously, the findings from this retrospective study of a large, contemporary cohort of commercially insured endometriosis patients indicate that comorbidities contribute substantially to the economic burden. For eight of 22 comorbidities associated with endometriosis, there were statistically significant absolute increases in healthcare spending after onset; for 21 comorbidities, there were significant relative increases in spending.

Finally, we have no information about whether there are any physiological mechanisms that tie together this wide variety of disease conditions identified as comorbidities with endometriosis per se. While it appears that the inflammatory and immune systems are altered in women with endometriosis in certain tissue [32], whether observations of this nature can be connected in any way to the pathophysiology of these comorbid conditions remains speculative and would require extensive future investigation.

\section{ACKNOWLEDGEMENTS}

Sponsorship for this study, article processing charges, and the open access fee were funded by AbbVie Inc. AbbVie participated in data analysis, interpretation of data, review, and approval of the manuscript. All authors had full access to all of the data in this study and take complete responsibility for the integrity of the data and accuracy of the data analysis.

Clinical expertise regarding comorbidity selection was provided by the late Dr. Craig A. Winkel, MD, who was paid consulting fees by AbbVie Inc. Medical writing services were provided by Suchin Virabhak of Medicus Economics. Medical writing services were funded by AbbVie Inc.

All named authors meet the International Committee of Medical Journal Editors (ICMJE) criteria for authorship for this manuscript, take responsibility for the integrity of the work as a whole, and have given final approval for the version to be published.

Disclosures. Ahmed Soliman is an AbbVie employee and may hold AbbVie stocks or stock options. Michael Snabes is an AbbVie employee and may hold AbbVie stocks or stock options. Andrew Epstein is an employee of Medicus Economics, which received a research contract to conduct this study with and on behalf of AbbVie. Scott Johnson is an employee of Medicus Economics, which received a research contract to conduct this study with and on behalf of AbbVie. Matthew Davis is an employee of Medicus Economics, which received a research contract to conduct this study with and on behalf of AbbVie. Eric Surrey is medical director at the Colorado Center for Reproductive Medicine, has served in a consulting role on research to AbbVie and is on the speaker bureau for Ferring Laboratories.

Compliance with Ethics Guidelines. This article does not contain any studies with human participants or animals performed by any of the authors.

Data Availability. The datasets analyzed during the current study are not publicly available because they are proprietary and data use agreements prohibit their release. Software code is available from the corresponding author on reasonable request.

Open Access. This article is distributed under the terms of the Creative Commons 
Attribution-NonCommercial 4.0 International License (http://creativecommons.org/licenses/ by-nc/4.0/), which permits any noncommercial use, distribution, and reproduction in any medium, provided you give appropriate credit to the original author(s) and the source, provide a link to the Creative Commons license, and indicate if changes were made.

\section{REFERENCES}

1. Simoens S, Hummelshoj L, D'Hooghe T. Endometriosis: cost estimates and methodological perspective. Hum Reprod Update. 2007;13(4):395-404.

2. Velebil P, Wingo PA, Xia Z, Wilcox LS, Peterson HB. Rate of hospitalization for gynecologic disorders among reproductive-age women in the United States. Obstet Gynecol. 1995;86(5):764-9.

3. American College of Obstetricians and Gynecologists. Practice bulletin no. 114: management of endometriosis. Obstet Gynecol. 2010;116(1):223-36.

4. Giudice LC. Clinical practice. Endometriosis. N Engl J Med. 2010;362(25):2389-98.

5. Eskenazi B, Warner ML. Epidemiology of endometriosis. Obstet Gynecol Clin North Am. 1997;24(2):235-58.

6. Fuldeore MJ, Soliman AM. Prevalence and symptomatic burden of diagnosed endometriosis in the United States: national estimates from a cross-sectional survey of 59,411 women. Gynecol Obstet Invest. 2017;82(5):453-61.

7. Soliman AM, Taylor H, Bonafede M, Nelson JK, Castelli-Haley J. Incremental direct and indirect cost burden attributed to endometriosis surgeries in the United States. Fertil Steril. 2017;107(5):1181-1190.e1182.

8. Hadfield R, Mardon H, Barlow D, Kennedy S. Delay in the diagnosis of endometriosis: a survey of women from the USA and the UK. Hum Reprod. 1996;11(4):878-80.

9. Soliman AM, Fuldeore M, Snabes MC. Factors associated with time to endometriosis diagnosis in the United States. J Womens Health. 2017;26(7):788-97.

10. Soliman AM, Yang H, Du EX, Kelley C, Winkel C. The direct and indirect costs associated with endometriosis: a systematic literature review. Hum Reprod. 2016;31(4):712-22.

11. Fuldeore M, Yang H, Du EX, Soliman AM, Wu EQ, Winkel C. Healthcare utilization and costs in women diagnosed with endometriosis before and after diagnosis: a longitudinal analysis of claims databases. Fertil Steril. 2015;103(1):163-71.

12. Mirkin D, Murphy-Barron C, Iwasaki K. Actuarial analysis of private payer administrative claims data for women with endometriosis. J Manag Care Pharm. 2007;13(3):262-72.

13. Simoens S, Dunselman G, Dirksen C, et al. The burden of endometriosis: costs and quality of life of women with endometriosis and treated in referral centres. Hum Reprod. 2012;27(5):1292-9.

14. Soliman AMSE, Johnson SJ, Davis M, Castelli-Haley $\mathrm{J}$, Snabes MC. Incidence of comorbidities among women with endometriosis: a retrospective matched cohort study. Fertil Steril. 2016;106(3):e277-8.

15. Grandi G, Toss A, Cortesi L, Botticelli L, Volpe A, Cagnacci A. The association between endometriomas and ovarian cancer: preventive effect of inhibiting ovulation and menstruation during reproductive life. Bio Med Res Intern. 2015. doi:10. $1155 / 2015 / 751571$.

16. Kvaskoff M, Mu F, Terry KL, et al. Endometriosis: a high-risk population for major chronic diseases? Hum Reprod Update. 2015;21(4):500-16.

17. Soliman AM, Yang H, Du EX, Wu EQ, Castelli-Haley J, Winkel C. Comorbidities and symptoms among endometriosis patients: a systematic literature review. Value Health. 2016;19(3):A172.

18. Somigliana E, Vigano P, Parazzini F, Stoppelli S, Giambattista E, Vercellini P. Association between endometriosis and cancer: a comprehensive review and a critical analysis of clinical and epidemiological evidence. Gynecol Oncol. 2006;101(2):331-41.

19. Melo AS, Rosa-e-Silva JC, Rosa-e-Silva AC, Poli-Neto $\mathrm{OB}$, Ferriani RA, Vieira CS. Unfavorable lipid profile in women with endometriosis. Fertil Steril. 2010;93(7):2433-6.

20. Santoro L, D'Onofrio F, Campo S, et al. Endothelial dysfunction but not increased carotid intima-media thickness in young European women with endometriosis. Hum Reprod. 2012;27(5):1320-6.

21. Mu F, Rich-Edwards J, Rimm EB, Spiegelman D, Missmer SA. Endometriosis and risk of coronary heart disease. Cir Cardiovasc Qual Outcomes. 2016;9(3):257-64. 
22. Tarride JE, Lim M, DesMeules M, et al. A review of the cost of cardiovascular disease. Can J Cardiol. 2009;25(6):e195-202.

23. Jacobson DL, Gange SJ, Rose NR, Graham NM. Epidemiology and estimated population burden of selected autoimmune diseases in the United States. Clin Immunol Immunopathol. 1997;84(3):223-43.

24. Yabroff KR, Lund J, Kepka D, Mariotto A. Economic burden of cancer in the United States: estimates, projections, and future research. Cancer Epidemiol Biomark Prev. 2011;20(10):2006-14.

25. Loftus PA, Wise SK. Epidemiology and economic burden of asthma. Intern Forum Allerg Rhinol. 2015;5(S1):S7-10.

26. Center for Medicare and Medicaid Services. National Health Expenditure Accounts: Methodology Paper, 2014.

27. Stuart EA. Matching methods for causal inference: a review and a look forward. Stat Sci. 2010;25(1):1-21.
28. Cameron AC, Miller DL A practitioner's guide to cluster-robust inference. J Hum Resour. 2015;50(2):317-72.

29. Alderman MH 3rd, Yoder N, Taylor HS. The systemic effects of endometriosis. Semin Reprod Med. 2017;35(3):263-70.

30. Mogensen JB, Kjaer SK, Mellemkjaer L, Jensen A. Endometriosis and risks for ovarian, endometrial and breast cancers: a nationwide cohort study. Gynecol Oncol. 2016;143(1):87-92.

31. Parazzini F, Esposito G, Tozzi L, Noli S, Bianchi S. Epidemiology of endometriosis and its comorbidities. Eur J Obstet Gynecol Reprod Biol. 2017;209:3-7.

32. Tamaresis JS, Irwin JC, Goldfien GA, et al. Molecular classification of endometriosis and disease stage using high-dimensional genomic data. Endocrinology. 2014;155(12):4986-99. 